\title{
URBAN DISASTERS
}

\section{3}

\section{The Jumbo Jet Crash in Amsterdam in 1992}

Olofsson $P$, Arturson $G * *$

* Karolinska Hospital, Stockholm, Sweden

** The University Hospital, Uppsala, Sweden

On Sunday evening, 5 October 1992, shortly after take-off from Schiphol Airport, a Cargo Boeing 747 Jumbo Jet of El Al crashed into a nine-story apartment building in a densely populated district of Amsterdam. Altogether, 45 to 50 apartments, a discotheque, and a club room were involved in a huge fire from 70 tons of flight kerosene and were destroyed completely. The primary estimate of the number of casualties was 200-250. Besides the huge fire, the major initial problem for the rescue workers and ambulances was the lack of functioning rendezvous points, leading to a chaotic traffic situation which limited access to the area.

The workload of the medical trauma teams was limited as expected in this type of disaster. Twelve persons were found dead on the ground after having jumped from their burning apartments. Altogether, 35 wounded were taken care of at the collection point. Of these, 28 were sent to the hospital and only nine (five severe-burn injuries, four with different types of blunt trauma, fractures, and minor-burn injuries) were admitted. The final death toll has been reported to be 70 persons. The identification process has been difficult as has the social part of the disaster; their management has been extended over a long time period. They also were complicated by the social situation in the area with more than 10,000 illegal immigrants and a high criminality.

The authors were sent to the scene of the accident as observers on behalf of KAMEDO, which is a Swedish Disaster Study Organization within the Department of Emergency and Disaster Planning at the Swedish National Board of Health and Welfare. 